\title{
EXCISION OF THE ENTIRE LATERAL CARTILAGE IN THE TREATMENT OF QUITTOR.
}

\author{
By R. PAIne, M.R.C.V.S., Assistant Hospital Surgeon, Royal \\ Veterinary College, London.
}

THE following operation was introduced here by Professor Woodruff from the Alfort Veterinary School; and since fairly satisfactory results ensued in the Free Clinique, in spite of the unfavourable surroundings connected with the patients subsequent to the operations, it was decided to practise the operation on two advanced cases of quittor among the hospital patients.

The operation is not of recent origin, but still it may be of interest if some of the chief details are briefly described.

The shoe having been previously removed, the patient is cast and the affected foot is firmly fixed. The wall is now rasped down immediately below the quittor, until an area corresponding in length to the cartilage has only a thin pellicle of horn covering the sensitive laminæ underneath. The heel is lowered in order to avoid any subsequent pressure, the patient is anæsthetised, and a tourniquet placed upon the limb.

After the operation area has been thoroughly scrubbed and rendered aseptic, and when the animal is completely under the influence of the anæsthetic, an incision is made through the wall immediately below and parallel with the coronary band, down to the underlying cartilage; this incision is made with a double-edged spear-pointed knife, and is carried along the entire length of the cartilage.

The knife is then insinuated into the incision in the wall, and the operator proceeds to separate the coronary band (above the knife) from the cartilage (below the knife) for its entire length, great care being taken not to injure the coronary band. When this has been accomplished, a single-bladed sage knife (right or left-handed, depending whether the anterior or posterior portion of the cartilage is being removed) is introduced into the incision. The first knife used has its cutting-edge forwards, and is gradually turned round the cartilage at the heel so as to get under its posterior end; with a single cut forwards the posterior portion of the cartilage is removed. The anterior portion is removed in a similar manner with the second sage knife.

Any small pieces of cartilage still remaining are carefully removed, the old wound at the coronet being thoroughly curetted.

Attention must now to be paid to the cavity produced, in order to render it completely aseptic; the method adopted in the hospital cases was as follows:-

First it was thoroughly douched out with a 4 per cent. solution of carbolic acid ; this was then soaked up with carbolised cottonwool until the cavity was quite dry. Pure chinosol was then rubbed thoroughly into the walls of the cavity, which was ultimately packed tightly with pledgets of carbolised cottonwool. A pad of cottonwool soaked in a $2 \frac{1}{2}$ per cent. solution of carbolic acid was then tightly bandaged over 
the operation area to prevent hamorrhage, which might be excessive if insufficient pressure were used.

The shoe was replaced and the horse allowed to rise.

These antiseptic precautions must be quite as thoroughly observed during the after-treatment, otherwise unsatisfactory results are sure to ensue.

If the operation has been conducted aseptically the dressing need not be interfered with for at least a week; but if there is the slightest suspicion of infection having occurred, then the entire dressing must be renewed and the wound cleansed. The cavity must not be packed so tightly in the subsequent dressings, in order to allow the granulation tissue to gradually fill up the cavity formed.

With the kind permission of Professor Penberthy I am enabled to report the following cases which were operated upon in the College Hospital :-

On I4th November I90I a Canadian vanner, the subject of an obstinate quittor complicated with an ulcerated heel, was operated upon according to the preceding method. On I6th December the horse trotted sound, and was discharged from the infirmary. Information was received from the owner on 25th March stating that the horse had gone on satisfactorily, and that "since his discharge the wound in the foot appears to be a complete cure."

On Ioth December I90 I a bay mare was received into the Infirmary suffering from an old-standing quittor on the inside of the near hind foot, complicated with badly ulcerated heels.

This mare was an extremely dangerous kicker, and, since it was a hind limb that was affected, the ordinary treatment by antiseptic injections was considered impracticable. The operation was performed on 14th December, and each time the foot required to be dressed it was always necessary to cast the mare; this had one serious disadvantage, since, during the mare's struggles against the restraint, the wound became several times severely bruised. Her recovery was undoubtedly retarded in this way.

On 24th January the mare trotted quite sound, but in this case, however, the foot was slightly deformed at the coronet, partially due no doubt to the bruising mentioned above. She was discharged from the Infirmary on 8th February.

The cases to be operated upon must, of course, be carefully chosen; but where other methods of treatment have failed, if the necessary conveniences are at hand, the operation is certainly worthy of a trial. If, however, strict antiseptic precautions cannot be fully carried out after the operation, it is certainly not to be advised. 